\title{
Model Diplomasi Perlindungan Pemerintah Indonesia terhadap Warga Negara Indonesia Pekerja Sektor Formal dan Informal di Luar Negeri
}

\author{
Paramitaningrum, Richa V. Yustikaningrum, \\ Galuh Dian Prama Dewi \\ Universitas Bina Nusantara, Jakarta
}

\begin{abstract}
Abstrak
Arus migrasi Warga Negara Indonesia (WNI) ke luar negeri semakin meningkat, baik untuk tinggal menetap, bekerja ataupun menempuh pendidikan di luar negeri. Bagi WNI yang bekerja, jumlah terbesar warga negara Indonesia berada di sektor informal, dan tersebar di kawasan Asia Timur dan Timur Tengah. Selain itu, cukup banyak WNI yang bekerja di sektor formal di luar negeri. Hal tersebut membawa konsekuensi yaitu setiap WNI baik yang bekerja tinggal dan menetap di luar negeri, memiliki hak yang sama untuk mendapatkan perlindungan dari Pemerintah Indonesia. Namun, menjadi persoalan berbeda ketika WNI pekerja sektor informal mengalami permasalahan, mereka tidak selalu bisa mendapatkan hak tersebut. Minimnya akses informasi, serta keterbatasan kemampuan perwakilan Indonesia di luar negeri menjadi penghambat untuk mengimplementasikan perlindungan terhadap. Warga Negara Indonesia. Tulisan ini bertujuan untuk mengetahui model diplomasi perlindungan pemerintah Indonesia terhadap WNI, terutama pekerja di sektor formal dan sektor informal. Proses pengumpulan data tulisan ini dilakukan melalui wawancara dengan para pengambil keputusan yang terlibat langsung serta menelaah berbagai studi terdahulu terkait bentuk diplomasi perlindungan terhadap WNI pekerja di sektor formal dan informal yang telah dipublikasikan, mengklasifikasikan upaya perlindungan terhadap berbagai situasi atau kasus yang dialami oleh warga negara kita tersebut di luar negeri serta pada akhirnya melakukan analisis atas berbagai pemberitaan di media massa.
\end{abstract}

Kata Kunci: Model Diplomasi Perlindungan, Migrasi, Pekerja Indonesia.

The migration flow of Indonesian Citizens migration is increasing, whether to stay, work or study abroad. For Indonesian citizens who work, the largest number of Indonesian citizens are in the informal sector, and spread across East Asia and the Middle East. In addition, quite a lot of Indonesians working in the formal sector abroad. It brings consequences that every Indonesian citizen who works, lives and resides abroad, has the same right to obtain protection from the Government of Indonesia. However, it becomes a different matter when the informal sector workers experience problems, they can't always get the right. The lack of access to information, as well as the limited ability of Indonesian. representatives abroad, are an obstacle to implementing the protection of Indonesian citizens. This paper aims to find out the model of Indonesian government protection diplomacy towards Indonesian citizens, especially workers in the formal and informal sectors. The data collection process of this paper was conducted through interviews with decision makers who were directly involved and reviewed previous studies related to the diplomacy form of protection of informal employers in the formal and informal sectors, classifying safeguards against various situations or cases experienced by our citizens abroad and in the end to analyze the various news in the mass media.

Key Words: Model of Protection Diplomacy, Migration, WNI, Indonesian workers. 
Tingginya arus migrasi khususnya bagi Warga Negara Indonesia (WNI) yang memilih untuk tinggal di luar negeri semakin nampak, baik untukyang tinggal menetap, memperoleh pekerjaan ataupun menempuh pendidikan di luar negeri. Jumlah komposisi terbesar WNI di luar negeri ada pada sektor informal, yang tersebar di wilayah Asia dan Timur Tengah, ditandai dengan peningkatan angka remitansi khususnya dari pekerja sektor informal sejak tahun 2004. Sebagai contoh remitansi yang diperoleh pada tahun 2004 sebesar 1.866 milyar dollar AS. Jumlah tersebut meningkat pada tahun 2005 menjadi 5.420 milyar dollar AS. Pada tahun 2008, jumlah remitansi bertambah menjadi 6.794 milyar dollar AS. Selain itu, data Kementerian Luar Negeri menyebutkan, jumlah WNI di luar negeri yang tercatat di Perwakilan RI adalah 3.141.354 (2007), 3.121.506 (2008), 3.147.211 (2009), 3.353.631 (2010), dan 3.075.104 (Januari-Juni 2011). Dari fluktuasi jumlah tersebut, kisaran 60\% sebagai TKI, 8\% merupakan tenaga kerja profesional, $6 \%$ berprofesi sebagai $\mathrm{ABK}, 20 \%$ adalah pelajar, sedangkan sebanyak 190.496 atau 6\% adalah WNI yang menikah dengan WNA (Tabloid Diplomasi 2011).

Gambaran tersebut belum sebanding dengan penerimaan remitansi dalam bentuk nyata dan jangka panjang terkait upaya-upaya perlindungan terhadap WNI khususnya pekerja migran yang telah berada di luar negeri. Meskipun dalam nota kesepahaman klausul terkait pasal perlindungan tenaga kerja telah dicantumkan negara penerima, tetapi hambatan internal justru muncul dari pekerja itu sendiri. Akumulasi kasus yang banyak merugikan pekerja sektor informal ini menggambarkan belum adanya solusi yang efektif dan bersifat jangka panjang. Seperti permasalahan yang dialami pekerja migran di era pemerintahan Presiden Susilo Bambang Yudhoyono yang sempat memunculkan inisiatif untuk pemberian telepon seluler bagi pekerja migran agar mempermudah komunikasi dengan perwakilan negara Indonesia yang di negara setempat, jika terjadi apaapa (Koban 2010).

Berbicara fakta dan situasi yang kerap menimpa WNI khususnya pekerja sektor informal, kita juga tidak bisa mengabaikan WNI lainnya yang tinggal, menetap dan bekerja di sektor formal di luar negeri. Setiap WNI yang berada, tinggal dan bahkan menetap di luar negeri, memiliki hak yang sama untuk mendapatkan perlindungan dari Pemerintah Indonesia. Sebagaimana konteks dalam penelitian yang telah dilakukan, tulisan ini memfokuskan pada upaya diplomasi perlindungan warga negara Indonesia di luar negeri, baik dengan mengamati dan memahami berbagai kasus yang seringkali menimpa warga negara Indonesia diluar 
negeri, termasuk pekerja sektor formal dan sektor informal. Selanjutnya tulisan ini juga menganalisa pemetaaan model diplomasi perlindungan yang diberikan pemerintah Indonesia terhadap warga negara Indonesia yang bekerja di sektor informal dan sektor formal di luar negeri. Melalui pemetaan tersebut dapat dilihat implikasinya dalam upaya perlindungan terhadap warga negara Indonesia di luar negeri.

\section{Studi Terdahulu}

Studi tentang permasalahan yang dialami pekerja migran di sektor informal yang ditempatkan di wilayah Timur Tengah dan Asia sudah banyak dilakukan. Secara spesifik, studi sebelumnya menjabarkan upaya perlindungan yang diberikan pemerintah Indonesia baik pada saat terjadinya kasus maupun pada saat tenaga kerja mengalami proses hukuman. Fokus berbagai studi ataupun penelitian tersebut beragam, mulai dari aspek hukum, aspek sosial, agama, dan kemanusiaan dengan mencoba menelusuri mendalam mengenai bentuk perlindungan hukum bagi pekerja migran yang melebihi batas waktu tinggal dan tidak terbatas pada kasus-kasus yang identik dengan kekerasan yang dialami pekerja migran tersebut.

Tulisan yang berjudul Perlindungan Hukum terhadap Tenaga Kerja Indonesia (TKI) yang Melebihi Batas Masa Tinggal (Overstay), melihat upaya perlindungan bagi TKI yang melebihi batas waktu tinggal, termasuk mekanismepembinaandanpengawasan, bantuanhukumdankekonsuleran, pembelaan atas pemenuhan hak-hak TKI serta upaya diplomatik yang diberikan. Asumsi awal studi ini memiliki kesamaan dengan studi lainnya yakni kesamaan persepsi dalam melihat kondisi pertumbuhan ekonomi yang relatif tinggi, kenyataannya tidak mampu memberikan solusi bagi berkurangnya angka pengangguran. Keterbatasan ini membuka potensi dan peluang bagi pekerja tersebut untuk bermigrasi sebagai pencari kerja di negara lain. Uniknya studi tersebut tidak menyangkal bahwa potensi meningkatnya arus migrasi pekerja migran tersebut juga sebanding dengan perilaku atau tindakan pelanggaran yang dilakukan para pekerja migran sector informal itu sendiri di negara dimana mereka ditempatkan. Disebutkan pula bahwa tidak sedikit yang mengalami kasus pelanggaran atau kekerasan di luar faktor si pekerja migran tersebut. Pemaparan selanjutnya adalah upaya perlindungan hukum khususnya bagi pekerja migran yang tinggal melebihi batas waktu tinggal rentan terhadap perilaku kesewenang-wenangan majikan dan upah yang sangat rendah. Selain itu 
dideskripsikan pula, faktor yang menjadi penyebab terjadinya kelebihan batas waktu tinggal oleh pekerja migran tersebut, perlindungan hukum serta tanggung jawab institusi baik PJTKI dan pengguna jasa (majikan) terhadap pekerja tersebut (Khair 2015).

Perspektifyang berbeda diberikan Tyas Retno Wulan yang mengkaitkan sisi migrasi dan Hak Asasi Manusia. Dalam studinya, Wulan menggambarkan ketidakdilan yang dialami oleh buruh migran Indonesia ketika menjalani fase pra-penempatan, penempatan, dan purna-penempatan. Melalui data yang disajikan, jumlah pekerja dari sektor informal terbesar berasal dari wilayah Lombok Timur, diikuti wilayah Indramayu dan Lombok Tengah (data hingga bulan April 2015). Secara unik, Wulan juga mencoba memetakan feminisasi migrasi terkait penempatan berdasarkan jenis kelamin pekerja migran tersebut, dimana Saudi Arabia, Malaysia dan Taiwan merupakan negara yang menjadi pilihan utama dalam penempatan pekerja migran perempuan. Studi ini sangat menarik karena mencoba mengolah data kuantitatif dan kualitatif seperti mengklasifikasikan jumlah kekerasan atau bentuk pemasalahan tenaga kerja dan selanjutnya menentukan hasil akhir dari fokus kajiannya (Wulan 2015).

Berdasarkan kedua perspektif tersebut, permasalahan terkait upaya perlindungan bagi WNI di luar negeri juga menjadi fokus utama Pemerintah Indonesia melalui Kementerian Luar Negeri (Kemenlu). Kajian yang dilakukan oleh Kemenlu mencoba memberikan gambaran upaya yang dilakukan tentang perlindungan terhadap warga negara mereka di luar negeri. Berbagai jenis permasalahan seperti narkotika, people smuggling, trafficking, tindak pidana penyiksaan, pelecehan, perkosaan, pembunuhan, dan overstayer, kecelakaan, penyanderaan, persoalan terkait kontrak kerja (gaji tidak dibayar, lembur, hari libur, sakit berat karena pekerjaan) telah menjadi fokus institusi ini. Dalam pemaparannya, Kemenlu juga telah mengupayakan berbagai strategi perlindungan terhadap warga negara baik melalui peraturan pemerintah, policy paper, kelompok kerja dengan melibatkan berbagai pihak agar adanya sinergi terkait permasalahan tersebut (Tabloid Diplomasi 2011).

Meski demikian, hasil temuan dan analisa studi-studi sebelumnya dapat memberikan kontribusi khususnya dalam mewujudkan diplomasi perlindungan yang efektif bagi WNI yang berada di luar negeri pekerja sektor formal maupun sektor informal yang telah tinggal dan menetap di luar negeri. Namun, hal yang membedakan penelitian ini dengan berbagai studi sebelumnya ialah bahwa selain berupaya mengkompilasikan berbagai 
situasi ataupun fakta terkait berbagai kasus yang dialami warga negara kita di luar negeri, penelitian ini berupaya untuk memperjelas kembali praktik diplomasi perlindungan dengan mencoba mengembangkan model pemetaan diplomasi perlindungan bagi warga negara kita di luar negeri.

\section{Diplomasi Perlindungan dalam Perspektif Hukum Internasional}

Dalam hukum internasional dinyatakan bahwa negara berkewajiban untuk melindungi warga negaranya yang tinggal di luar negeri. Perlindungan suatu negara terhadap warga negaranya yang berada di luar negeri disebut Diplomatic Protection. Secara konsep, diplomatic protection adalah "action taken by a state against another state in respect of injury to the person or property of national caused by an internationally wrongful act or omission attributable to the latter state" (Forcese 2006, 374-375).

Lebih lanjut tulisan Craig Forcese juga menyebutkan untuk melaksanakan perlindungan diplomatik terdapat tiga syarat yang harus dipenuhi (Craig Forcese 2006, 375-384): (1) An International wrong, bahwa suatu negara pengirim mempunyai kewajiban untuk memberikan perlindungan terhadap warga negaranya diluar negeri apabila terjadi pelanggaran hukum internasional yang dilakukan oleh warganegara tersebut. Hal ini mengacu pada pasal 3 Konvensi Wina (VCDR) 1961 tentang Hubungan Diplomatik yang menyatakan, "protecting in the receiving state the interests of the sending state and its nationals, within the limits permitted by international law" (United Nations 2005); (2) Exhaustion Local Remedies, yaitu perlindungan diplomatik suatu negara (bantuan hukum suatu negara terhadap warga negaranya untuk melakukan tuntutan hukum kepada negara lain) akan dilakukan apabila warga negara tersebut telah menempuh upaya hukum lokal di negara penerima; (3) Link of Nationality yaitu perlindungan diplomatik yang hanya dapat dilakukan oleh negara yang warga negaranya mengalami tindakan pelanggaran hukum internasional oleh negara lain. Hal ini diatur dalam pasal 3 ayat (1) the International Law Commission Draft Articles on Diplomatic Protection 2006 (United Nations 2006) yang menyatakan bahwa: "The state entitled to exercise diplomatic protection is the State nationality." Pasal selanjutnya menyatakan bahwa, "for the purposes of diplomatic protection of natural persons, a state of nationality means a state whose nationality the individual sought to be protected has acquired, descent, succession of states, naturalization or in any other manner, not inconsistent 
with international law.” Artinya kewarganegaraan seseorang dapat diperoleh karena kelahiran, keturunan, suksesi negara, naturalisasi atau cara-cara lainnya yang tidak bertentangan dengan hukum internasional.

Persyaratan tersebut sesuai dengan prinsip kewarganegaraan pasif yang menetapkan bahwa suatu negara mempunyai yurisdiksi atas orang yang melakukan pelanggaran hukum di wilayah negara lain, yang akibat hukumnya menimpa warga negaranya. Oleh karena itu, jika negara tempat terjadinya pelanggaran tidak mampu dan tidak mau menghukum pelaku pelanggaran, maka negara yang warga negaranya dirugikan berwenang untuk menghukum. Tanggung jawab dan kewajiban suatu negara untuk melindungi warga negaranya yang berada di luar negeri diemban oleh fungsi diplomatik dan konsuler suatu negara.

Fungsi Konsuler di atur dalam Pasal 5 Konvensi Wina 1963 tentang Hubungan Konsuler. Dalam salah satu butir Pasal 5 Konvensi Wina 1963 tersebut dinyatakan bahwa, "Consular functioning consit in: protecting in the receiving State the interests of sending state and of its nationals, both individuals and bodies corporate, within the limits permitted by international law" (United Nations 2005). Berdasarkan pernyataan tersebut dapat diketahui bahwa sesungguhnya perwakilan konsuler negara pengirim di negara penerima berkewajiban untuk melindungi warga negaranya dan kepentingan mereka.

\section{Dasar Hukum dan Komitmen Perlindungan WNI oleh Pemerintah Indonesia}

Sebagai bentuk komitmen perlindungan WNI baik pekerja sekor formal maupun informal di luar negeri, pemerintah Indonesia dalam upayanya menggunakan panduan sebagaimana tercantum dalam Amanah Konstitusi - pertama, yakni sebagai berikut: (1) Alinea 4: "Kemudian daripada itu untuk membentuk suatu pemerintah negara Indonesia yang melindungi segenap bangsa Indonesia dan seluruh tumpah darah Indonesia dan untuk memajukan kesejahteraan umum, mencerdaskan kehidupan bangsa, dan ikut melaksanakan ketertiban dunia...”; (2) Fungsi, Misi Diplomatik - Kedua, VCDR 1961, Art.3 (1b): "Protecting in the receiving State the interests of the sending State and of its nationals, within the limits permitted by international law". (United Nations 2005); (3) Fungsi Misi Konsular - Pertama, VCCR 1963, Art.5 (a): "Protecting in the receiving State the interests of the sending State and of its national, both individuals and 
bodies corporate within permitted by international law. (United Nations 2005); (4) UU Hubungan Luar Negeri - Bab V Perlindungan WNI, Pasal 19 (b): "Perwakilan RI berkewajiban: memberikan pengayoman, Indonesia di luar negeri, sesuai dengan peraturan perundang-undangannasional serta hukum dan kebiasaan internasional. (Kementrian Luar Negeri, t.t); (5) UU No. 21 tahun 2007 tentang Pemberantasan Tindak Pidana Perdagangan Orang/TPPO (Kementrian Luar Negeri, t.t). Selain itu mengacu pada Hukum Perlindungan dan Penanganan Korban TPPO di Luar Negeri yakni: Protocol to Prevent, Suppress and Punish Trafficking in Persons Espcially Women and Children, supplementing the United Nations Convention against Transnational Organised Crime (Palermo Protocol 2000) dan UU Republik Indonesia.

\section{Tabel 1 - Dasar Hukum Perlindungan Korban TPPO oleh Kemlu dan Perwakilan RI}

\begin{tabular}{|l|l|}
\hline \multicolumn{1}{|c|}{ Dasar Hukum } & \multicolumn{1}{|c|}{ Isi } \\
\hline $\begin{array}{l}\text { Article 6 dan Article } \\
\text { 8 Palermo Protocol }\end{array}$ & $\begin{array}{l}\text { • Article 6: Protection of Victims } \\
\text { Article 8: Repatriation of Victims }\end{array}$ \\
\hline $\begin{array}{l}\text { Bab V UU No. 37 } \\
\text { Tahun 1999 }\end{array}$ & $\begin{array}{l}\text { - Dilakukan melalui 3 (tiga) strategi } \\
\text { utama: pencegahan deteksi dini, } \\
\text { dan perlindungan cepat dan tepat }\end{array}$ \\
& $\begin{array}{l}\text { Implementasinya melibatkan } \\
\text { stakeholders terkait, baik didalam } \\
\text { maupun diluar negeri }\end{array}$ \\
\hline $\begin{array}{l}\text { Pasal 54 UU No.21 } \\
\text { Tahun 2007 }\end{array}$ & $\begin{array}{l}\text { Melindungi kepentingan WNI } \\
\text { korban di luar negeri } \\
\text { Memfasilitasi pemulangan WNI } \\
\text { korban ke Indonesia }\end{array}$ \\
\hline
\end{tabular}




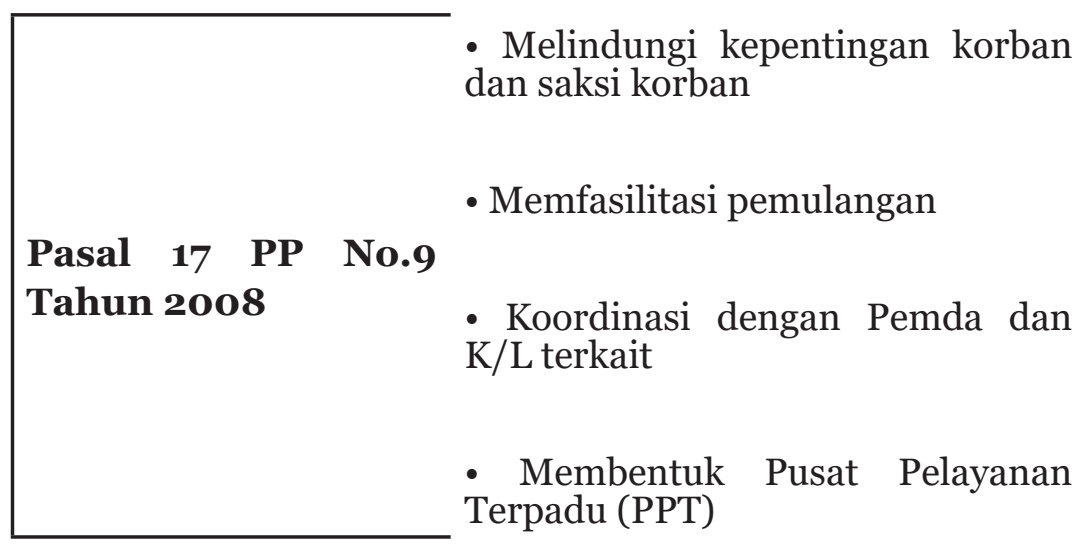

Jaelani (2016) juga menjelaskan terkait 5 (lima) dasar hukum perlindungan WNI di luar negeri, yakni: (1) Undang-Undang Dasar 1945 alinea keempat yang berbunyi "Kemudian daripada itu untuk membentuk suatu pemerintah negara Indonesia yang melindungi segenap bangsa Indonesia dan seluruh tumpah darah Indonesia...”; (2) Konvensi Wina 1961 dan 1963 mengenai hubungan diplomatik antar negara, yang salah satu pasalnya mengatur perlindungan warga negara di luar negeri, yang kemudian menjadi acuan bagi UU No 21 tentang Human Trafficking; (3) Undang-Undang Nomor 37 Tahun 1999 mengenai hubungan luar negeri, tepatnya dalam $\mathrm{BAB} V$, yang mengatur perlindungan WNI oleh perwakilan RI di luar negeri; (4) Undang-Undang Nomor 39 Tahun 2004, mengatur mengenai penempatan dan perlindungan Tenaga Kerja Indonesia di luar negeri; (5) Peraturan Menteri Luar Negeri Nomor 4 Tahun 2008 tentang pelayanan warga pada perwakilan RI di luar negeri.

Untuk mendukung kegiatan operasional di kantor perwakilan pemerintah Indonesia di luar negeri, misalnya identifikasi korban, Shelter, pencatatan kronologi kasus yang terjadi, persiapan dokumen Perjalanan termasuk tiket Repatriasi, seperti yang sudah disebutkan pada bab sebelumnya bahwa sangat penting untuk membentuk Pelayanan Warga (Citizen Service) pada 24 Perwakilan RI di Luar Negeri, dengan pertimbangan: (a) Jumlah WNI yang berada diluar negeri terus meningkat; (b) Jumlah kasus yang melibatkan WNI dalam tiga tahun terakhir khususnya WNI Sektor informal; (c) Profil WNI yang kian beragam; (d) Perbedaan Peraturan hukum negara-negara penerima yang membutuhkan penyesuaian serta strategi yang tepat; (e) Penerapan hukuman mati di negara penerima yang seringkali memicu ketegangan hubungan diplomatik dalam kasus-kasus WNI pekerja sektor informal; (f) Jumlah WNI yang tidak memiliki izin tinggal; dan luas cakupan wilayah akreditasi, berikut ialah Tabel 2 terkait 
Cakupan wilayah perluasan kantor perwakilan dari tahun 2007 hingga saat ini:

\section{Tabel 2 - Cakupan Wilayah Perluasan Kantor Perwakilan (Tahun 2007-2015)}

\begin{tabular}{|l|l|}
\hline \multicolumn{1}{|c|}{ Tahun } & \multicolumn{1}{c|}{ Tempat } \\
\hline $\mathbf{2 0 0 7}$ & $\begin{array}{l}\text { Amman, Bandar Seri Begawan, } \\
\text { Damascus, Doha, Seoul, Singapore }\end{array}$ \\
\hline $\mathbf{2 0 0 8}$ & $\begin{array}{l}\text { Abu Dhabi, Kuala Lumpur, Kuwait } \\
\text { City, Riyadh, Dubai, Hong Kong, } \\
\text { Jeddah, Johor Bahru, Kota Kina- } \\
\text { balu }\end{array}$ \\
\hline $\mathbf{2 0 0 9}$ & $\begin{array}{l}\text { Tokyo, Osaka, Penang, Kuching, } \\
\text { New York, Los Angeles, Sydney, } \\
\text { Darwin }\end{array}$ \\
\hline $\mathbf{2 0 1 2 - 2 0 1 5}$ & $\begin{array}{l}\text { Rencana: } \\
\text { Cairo, Den Haag, Muscat, Mana- } \\
\text { ma, Tawau, Abuja, Beijing/Guang- } \\
\text { zhou, Ankara, Taipei }\end{array}$ \\
\hline
\end{tabular}

Aturan-aturan hukum yang disebutkan diatas merupakan dasar bagi setiap tindakan penanganan kasus ataupun peristiwa yang menimpa WNI di luar negeri. Selanjutnya efektifitas aturan-aturan tersebut dalam menangani berbagai permasalahan yang dihadapi WNI karena tindakan mereka sendiri, seperti contoh WNI yang overstayer, illegal entry ataupun terlibat kasus kriminal di luar negeri, dijelaskan oleh Kasubdit Pengawasan Kekonsuleran Kementrian Luar Negeri Krisna Jaelani. Ditambahkan bahwa kendala yang paling sering dihadapi oleh para staff KBRI atau kantor perwakilan RI di luar negeri adalah: (a) Rendahnya kesadaran diri WNI untuk wajib lapor secara berkala ke kantor perwakilan. Banyak yang enggan melapor dan baru melapor ke kantor perwakilan saat menghadapi masalah. Tidak jarang para WNI baru melaporkan penderitaan dan kerugian bagi mereka; (b) Lambatnya komunikasi antar pemerintah setempat, yang sering terjadi ketika ada TKI kabur dari rumah majikan. Kendala ini bisa dari sisi bahasa, sikap petugas kepolisisan setempat, majikan yang tidak kooperatif ataupun identitas TKI bermasalah tersebut kabur atau tidak jelas, sehingga mempersulit koordinasi baik sehingga upaya penanganan dan solusi selama ini menjadi terkesan lambat; (c) Unpredictability, terjadinya suatu kasus yang menimpa WNI tidak pernah bisa diprediksi, sedangkan staff perwakilan memiliki tugas dan 
fokus yang beragam, sehingga harus mengalokasikan waktu ekstra untuk menangani kasus itu lebih mendalam; (d) WNI yang dikategorikan bandel atau bermasalah. Saat terjadi masalah dengan WNI notabene TKI sektor informal, menyulitkan posisi staff perwakilan, dikarenakan identitas dan dokumen yang dimiliki terkait data pribadi mereka seperti nama, alamat tinggal dan usia yang kemudiandipalsukan.

Dikarenakan jumlah WNI yang tersebar di luar negeri itupun juga sangat banyak, maka salah satu upaya penanganan problem saat ini ialah dengan memberikan fasilitas pembekalan saat TKI tersebut tiba di negara penerima, sosialisasi sms/hotline ke kantor perwakilan setempat apabila terjadi peristiwa yang membahayakan keselamatannya, seperti Kedutaan Besar Republik Indonesia (KBRI) Bangkok yang membuka layanan online 24 jam. Contoh lainnya, berdasarkan data KBRI Bangkok, 7 November 2016 lalu jumlah warga negara Indonesia yang berada di Thailand tercatat 3567 orang WNI. Keseluruhan dari jumlah tersebut terekam melalui Program SAWADI (Sistem Aplikasi Wajib Lapor Diri) yang bisa diakses secara online, dapat mendeteksi jumlah WNI yang masih tinggal, jumlah WNI yang sudah kembali ataupun pindah ke negara lain melalui pelaporan yang disampaikan. Data WNI tersebut juga diperoleh dari Konsulat RI di Songkla yang kemudian diintegrasikan dengan KBRI Bangkok.

\section{Klasifikasi Kasus-kasus yang dialami WNI di Luar Negeri}

Tingginya arus migrasi khususnya bagi WNI di luar negeri, belum berbanding lurus dengan diterimanya sejumlah besar remitansi dengan wujud konkrit dan jangka panjang terkait upaya-upaya perlindungan terhadap warga negara kita khususnya pekerja migran yang telah berada di luar negeri. Diperlukan pemahaman mendalam dari seluruh pihak terkait tidak hanya terbatas pada pemerintah Indonesia yang direpresentasikan oleh Kementrian Luar Negeri, Kementrian Tenaga Kerja ataupun Instasi Penyalur Tenaga Kerja, serta perhatian dan kerjasama penuh dari warga negara Indonesia baik yang memiliki rencana untuk bekerja diluar atau menetap ataupun yang telah tinggal di luar negeri. Meskipun terdapat nota kesepahaman klausul terkait pasal perlindungan tenaga kerja telah dicantumkan dengan negara penerima, tetapi hambatan internal yang muncul dari pekerja itu sendiri dan juga akumulasi mencuatnya kasus yang banyak merugikan pekerja sektor informal ini membuktikan nota kesepahaman belum banyak memberikan solusi efektif dan jangka panjang. 
Sekitar 2,8 juta jiwa Warga Negara Indonesia tercatat berada dan tinggal di luar negeri. Merujuk pada UU Keimigrasian bahwa bagi warga negara Indonesia yang tinggal lebih dari 1 tahun wajib melapor pada kantor perwakilan setempat. Hal ini bertujuan untuk mempermudah pengawasan dan rekam administrasi serta untuk mempermudah penanganan masalahmasalah terkait WNI di luar negeri yang kerap terjadi, seperti WNI yang menikah dengan WNA, pelajar overstayer ataupun pekerja unskilled yang kabur dari rumah majikan. Berbagai kasus atau peristiwa tersebut selama ini telah menjadi perhatian pemerintah Indonesia baik di kantor perwakilan pemerintah Indonesia di luar negeri ataupun di Indonesia sendiri dan faktor penyebabnya digolongkan dalam empat kategori utama sebagaimana digambarkan pada tabel di bawah ini.

Tabel 3 - Kategori Kasus terkait WNI di Luar Negeri

\begin{tabular}{|l|l|l|}
\hline No. & \multicolumn{1}{|c|}{ Kasus } & \multicolumn{1}{c|}{ Faktor Penyebab } \\
\hline 1. & $\begin{array}{l}\text { Keimigrasian dan } \\
\text { Kewarganegaraan }\end{array}$ & $\begin{array}{l}\text { a. illegal entry/tanpa dokumen } \\
\text { resmi dan sah } \\
\text { b. Overstayer di Eropa, (Belanda), } \\
\text { Jeddah, AS } \\
\text { c. Status Kewarganegaraan, } \\
\text { menikah dengan WNA, mengala- } \\
\text { mi perceraian namun terganjal } \\
\text { dengan hak asuh anak (usia 21 } \\
\text { tahun baru dapat memilih kewar- } \\
\text { ganegaraan sendiri) }\end{array}$ \\
\hline 2. & Ketenagakerjaan & $\begin{array}{l}\text { Gaji tidak dibayarkan, diperlaku- } \\
\text { kan kasar dan mengalami pelece- } \\
\text { han seksual, kerja tidak sesuai } \\
\text { kontrak (tidak dibayarkan lem- } \\
\text { burnya), berselisih paham, jam } \\
\text { kerja tidak sesuai }\end{array}$ \\
\hline
\end{tabular}




\begin{tabular}{|l|l|l|}
\hline 3. & Masalah Hukum & $\begin{array}{l}\text { a. Masalah Hukum Perdata (Per- } \\
\text { janjian, Hak Harta, Perkawinan/ } \\
\text { Perceraian, Waris, Adopsi Anak, } \\
\text { dsb) } \\
\text { b. Masalah Hukum Pidana baik } \\
\text { sebagai pelaku atau korban } \\
\text { (Narkoba, Pembunuhan, Pen- } \\
\text { curian, Penyiksaan, Perkosaan, } \\
\text { terlibat tindakan perampokan, } \\
\text { narkoba (baik sebagai pelaku atau } \\
\text { korban) }\end{array}$ \\
\hline 4. & Lain-lain & $\begin{array}{l}\text { a. Sakit, umroh lalu meninggal, } \\
\text { wisata mengalami kecopetan, } \\
\text { b. Repatriasi/Evakuasi Dalam } \\
\text { Hal Bencana Alam atau Keadaan } \\
\text { Darurat Lainnya } \\
\text { c. Hilang Kontak } \\
\text { d. Terlantar }\end{array}$ \\
& & \\
& &
\end{tabular}

Tabel diatas sesuai dengan permasalahan yang juga dihadapi WNI di Thailand, seperti misalnya pelanggaran keimigrasian, pengaduan gaji/klaim asuransi yang tidak dibayar (ABK dan korban kecelakaan), pelanggaran hukum pidana (penyelundupan narkotika, pemalsuan dokumen perjalanan, perampokan dan pencurian, illegal fishing), kehilangan paspor, uang dan lain-lain. Adapun jumlah kasus yang menimpa WNI di Luar negeri dan Persentase kasus yang berhasil diselesaikan sejak tahun 2011, dapat dilihat pada Tabel 4 di bawah ini.

\section{Tabel 4 - Penanganan Kasus WNI/TKI di Luar Negeri}

\begin{tabular}{|l|l|l|}
\hline Tahun & Total Kasus WNI & Diselesaikan \\
\hline 2011 & 3.242 & $2.050(63 \%)$ \\
\hline 2012 & 20.668 & $12.477(60 \%)$ \\
\hline 2013 & 25.802 & $17.341(67 \%)$ \\
\hline 2014 & 17.052 & $13.043(76 \%)$ \\
\hline 2015 & 31.506 & $19.530(62 \%)$ \\
\hline
\end{tabular}




\begin{tabular}{|l|l|l|}
\hline $\begin{array}{l}\text { 2016 (1 Jan s.d 12 } \\
\text { Juni 2016) }\end{array}$ & $\begin{array}{l}\text { 9.612 TKI 9130 } \\
\text { (ABK 203, Non TKI } \\
\text { 258) }\end{array}$ & $6639(68 \%)$ \\
\hline
\end{tabular}

Berdasarkan hasil tabel tersebut, terlihat fluktuasi jumlah kasus WNI di luar negeri dan mengalami peningkatan di tahun 2015 sejumlah 31.506 kasus dengan total persentase sebesar hanya 62\%, apabila dibandingkan dengan tahun 2013 dimana sebanyak 25.802 kasus yang menimpa WNI, jumlah penanganan mampu mencapai $67 \%$. Jika mengamati kasus WNI di tahun 2014, dimana angka kasus mengalami penurunan hingga 17.052 kasus dengan hasil penanganan kasus mencapai 76\% dengan tahun 2016 di semester pertama, maka baik jumlah kasus dan penanganannya sudah jauh lebih baik dan menunjukkan perubahan yang signifikan.

\section{Praktik Kebijakan Perlindungan Warga Negara Indonesia di Luar Negeri}

Dengan peningkatan arus WNI yang berkunjung, tinggal, dan menetap di luar negeri serta banyaknya kasus yang dialami WNI di luar negeri, Menteri Luar Negeri Retno Marsudi mengemukakan perlunya terobosan kebijakan seperti integrity database system, e-perlindungan, iklan, dialog secara efektif kepada masyarakat agar mereka memahami dan mendukung upaya pemerintah dalam memberikan perlindungan. Salah satu contohnya ialah sosialisasi dini terkait keamanan dan keselamatan WNI saat dalam melakukan perjalanan, seperti tata cara bermigrasi yang aman ke luar negeri, diawali dengan membawa identitas diri dan dokumen yang sah (paspor, visa ke tempat tujuan, jika diperlukan), ketika di bandara untuk tidak menerima barang dari orang lain (baik penitipan ataupun menitipkan). Upaya terbaru lain adalah melalui layanan SafeTravel- yang dapat diakses melalui Google Play. Dalam hal ini, Kemenlu berperan dalam mengelola dan mengembangkan aplikasi tersebut untuk mempermudah dan mendukung program perlindungan pemerintah bagi WNI di luar negeri. Langkah lainnya yakni mencanangkan Public Awareness Campaign berupa kunjungan ke wilayah yang menjadi kantong TKI melalui kegiatan langsung, ataupun melalui siaran-siaran radio, bekerjasama dengan universitas dan pemeritah daerah (Jaelani 2016).

Berdasarkan pengalaman sebelumnya, prosedur pelayanan bagi WNI 
di luar negeri, baik yang bekerja sebagai pekerja informal ataupun yang professional, secara umum menggunakan layanan resmiviasms atau hotline ataupun datang langsung ke kantor perwakilan. Adanya keterbatasan staff di kantor perwakilan ataupun kasus yang terjadi seringkali berbeda wilayah, sehingga dikembangkan pembinaan dan pemberdayaan WNI di luar negeri melalui komunitas-komunitas WNI di luar negeri sesuai area, atau berbasis keagamaan seperti PPI (Perkumpulan Pelajar Indonesia), Grup Pengajian, Persekutuan doa, dan lain-lain. Tujuan pembinaan ini ialah sebagai mata dan telinga tidak hanya bagi WNI namun juga bentuk kerjasama antara pemerintah dan komunitas WNI di luar negeri untuk mempermudah pengawasan dan perlindungan bagi WNI tersebut. Selain itu melihat fluktuasi angka tingkat kasus yang dialami WNI di luar negeri dan bervariasinya peraturan negara penerima, sementara jumlah kantor perwakilan Indonesia hanya 132 kantor, maka program Citizen Services diharapkan dapat membantu pengawasan dan perlindungan bagi WNI di luar negeri. Program ini merupakan sebuah satuan tugas atau unit perlindungan yang beraggotakan berbagai instansi yang terkait. Dicanangkan sejak tahun 2008, Citizen Services memang belum terlalu efektif karena keterbatasan jumlah kantor perwakilan dan luasnya daerah yang harus ditangani.

Dalam praktik perlindungan WNI di luar negeri, sebagai contoh, KBRI Bangkok menerapkan 3 (tiga) strategi yakni pertama, pencegahan, dimana KBRI Bangkok menyampaikan diseminasi tentang peraturan Keimigrasian Thailand, baik melalui website, atau mendatangi sentrasentra pelajar/WNI, dan hingga saat ini tercatat telah melakukan 4 (empat) kali sosialiasi keimigrasian di Thailand. Kedua, deteksi dini dengan membangun jejaring dengan aparat pemerintah setempat dan unsur-unsur masyarakat Indonesia di Thailand, termasuk pengembangan sistem hotline dan piket 24 jam terkait perlindungan WNI. Ketiga, immediate response, cepat tanggap atas kejadian yang meimpa WNI di Thailand. Misalnya, saat terjadi kecelakaan pada 16 Agustus 2016 lalu di Kuil Erawan, pendampingan dalam persidangan khususnya kasus dugaan pidana pada WNI yang terlibat, fasilitas penerjemah bagi WNI baik di penjara Thailand ataupun di Rumah Detensi Imigrasi. Selain itu, KBRI Bangkok selalu berkoordinasi erat dengan komunitas Indonesia di Thailand, seperti Permitha (Persatuan Mahasiswa Indonesia di Thailand) terkait sosialisasi Keimigrasian dan Kekonsuleran, peluncuran Program SAWADI khususnya dalam pembuatan program SAWADI, dan integrasi Data Lapor Diri Manual ke Data SAWADI (KBRI Bangkok 2016). 
Selain itu KBRI Singapura, juga telah meluncurkan kartu untuk melindungi dan memonitor para Tenaga Kerja Indonesia (TKI) khususnya, yakni Kartu Sakti Pekerja Indonesia Singapura (KPIS). Kartu ini selain untuk pengawasan bagi TKI tersebut, juga memberikan akses kepada TKI terhadap sistem perbankan nasional Indonesia (Ngurah Swajaya, detikFinance). Berdasarkan hasil temuan terkait dengan upaya perlindungan pemerintah Indonesia terhadap WNI Pekerja Sektor Formal dan Informal, kasus yang paling sering terjadi adalah overstayer dan TKI undocumented. Dalam hal, ini Pemerintah Indonesia menggunakan Skema Pemulangan WNI Overstayer dan TKI Undocumented dengan rincian sebagai berikut: (a)sosialisasi; (b)pendataan WNI;(c)penyelesaian adminitrasi untuk kepulangan; (d)penampungan; (e)pemulangan.

\section{Standart Operating Procedure dan Analisa Model Perlindungan WNI di Luar Negeri}

Selama ini, masalah yang ditangani pemerintah Indonesia lebih banyak terkait dengan WNI di sektor informal. Sebagai pengembangan langkah perlindungan yang selama ini lebih diarahkan pada perlindungan secara hukum tersebut, pemerintah Indonesia secara intensif bekerjasama dengan PJTKI atau institusi non Kemenlu. Tindakan tersebut merupakan sikap real pemerintah atas klausul Konvensi Wina 1963 bahwa pemerintah setempat wajib menginformasikan ke kedutaan besar atau kantor perwakilan negara apabila terdapat warga dari negara perwakilan tersebut ditangkap. Sayangnya, fakta yang terjadi di lapangan, kantor perwakilan tersebut seringkali terlambat dalam memperoleh informasi. Beberapa temuan yang menjadi faktor penyebab keterlambatan tersebut, terbagi dalam 2 (dua) area yakni luar negeri dan domestik. Untuk luar Negeri, seperti: (a)Ketidaktahuan institusi yang menangkap; (b)Pendekatan terkait akses kekonsuleran diatur secara bilateral, dalam pembuatan MoU (mandatory conculer notification); (c)Kasus hukuman mati, seperti yang terjadi di Malaysia, diupayakan dilakukan diplomasi dengan negara penerima (asas pemaafan dari Sultan) namun tetap mengupayakan perlindungan dan menghormati prosedur hukum pemerintah setempat. Sebagai catatan, perlindungan yang diberikan pemerintah Indonesia selama ini lebih pada perlindungan ke ranah hukum (apakah WNI kita diperlakukan baik, pendampingan bahasa), dan bukan pada posisi untuk mengambil alih tanggung jawab atas tindakan kesalahan WNI yang terlibat kasus kejahatan/masalah mereka. 
Sedangkan dari sisi domestik, bahwa terdapatnya kerjasama antar institusi yakni Kemenlu, B2NPTKI (Badan Nasional Penempatan dan Perlindungan Tenaga Kerja Indonesia) dan Kementerian Tenaga Kerja. Untuk beberapa kasus WNI yang bermasalah dan dipulangkan ke tanah air dilakukan penanganan khusus dengan melibatkan institusi lain yang terkait. Sebagai contoh: (a)WNI Korban Human Trafficking, Bareskrim dan Kementerian Sosial melalui Rumah Perlindungan Trauma Center untuk upaya rehabilitasi psikologis; (b)BNN (Badan Narkotika Nasional) untuk memetakan upaya penyelundupan narkotika dan obat terlarang; (c) BN2PTKI dan Dirjen Perhubungan Laut untuk ABK korban sandera.

Hambatan perlindungan terhadap WNI juga ditemukan di KBRI Bangkok. Dalam laporan, disebabkan oleh beberapa hal: pertama, wilayah territorial yang relatif luas seringkali diperlukan waktu untuk melakukan koordinasi dengan apparat terkait guna melakukan upaya perlindungan. Kedua, keterbatasan kemampuan berbahasa Thailand khususnya terkait dengan bidang hukum sehingga menimbulkan kesulitan, dan KBRI Bangkok sangat membutuhkan staff dengan kemampuan khusus agar upaya perlindungan menjadi optimal. Ketiga, perilaku WNI itu sendiri yang mempersulit upaya perlindungan, menolak memberi kontak atau alamat keluarga di Indonesia serta menolak dipulangkan ke Indonesia (KBRI Bangkok 2016).

Jaelani mengungkapkan bahwa selama ini tidak ada perbedaan dalam praktik upaya perlindungan WNI di luar negeri terhadap pekerja sektor formal dan sektor informal, karena situasi yang terjadi di lapangan sangat bergantung pada tingkat masalah dan kerjasama dari pihak yang terlibat. Contohnya, masalah yang dialami oleh WNI yang bekerja di sektor formal, didominasi oleh keterbatasan hak dan kewajiban terkait dengan pekerjaan (uang lembur yang tidak dibayarkan, perselisihan dengan perusahaan yang menjadi tempat kerja mereka). Sedangkan untuk pelajar lebih seringkali dihadapkan pada kasus tinggal yang melebihi batas waktu atau mengalami sakit parah dan memerlukan perhatian khusus. Bagi WNI yang menikah dengan WNA dan mengalami masalah dalam pernikahan mereka yang berujung pada perceraian, seringkali terjadi masalah perebutan hak asuh anak dan hal ini diadukan sebagai kasus penculikan. Kantor perwakilan setempat kerap kali menangani persoalan-persoalan seperti ini. Berbeda dengan instansi keuangan (bank) /perusahaan swasta yang membuka kantor cabang di luar, apabila ada kendala atau masalah hukum mayoritas sudah diantisipasi dengan memiliki prosedur sendiri dan hanya meminta bantuan hukum dari kantor perwakilan berupa bantuan pengacara atau pendampingan saja. 
Dalam rangka upaya peningkatan diplomasi perlindungan yang diberikan pemerintah Indonesia terhadap WNI yang bekerja di sektor informal dan sektor formal di luar negeri, terkait masalah TKI di luar negeri, maka prosedur yang dilakukan ialah sebagai berikut: (a) Tahap 1: TKI melalui BN2PTKI, mengadakan briefing mengenai hal-hal yang terkait keberangkatan atau pembekalan tentang apa saja yang harus dilakukan, bagaimana tata cara kehidupan di negara penerima ataupun terkait bagaimana jika mengalami masalah; (b) Tahap 2: Kantor Perwakilan mengadakan "Welcoming Program" untuk menunjukkan tanggung jawab pemerintah Indonesia terhadap WNI, memberikan panduan tentang hukum setempat, sosialisasi tentang apa yang harus dilakukan saat menghadapi masalah, tentang hak dan kewajiban WNI selama di luar negeri. (Jaelani 2016).

Mekanisme tersebut diarahkan agar sejalan dengan upaya Menteri Luar Negeri Retno L.P Marsudiyangingin memperbaikipelayanan, perlindungan WNI di luar negeri. Melalui SMS Blast bagi setiap WNI yang tiba di luar negeri, yang berisi nomor telepon kantor perwakilan, layanan hotline 24 jam dalam 7 (tujuh) hari, serta penerapan 3 (tiga) langkah strategis perlindungan WNI, yakni prevention, early detection dan immediate response. Sedangkan untuk praktik perlindungan dan standar operasional bagi WNI dengan kasus overstayer, diterapkan proses pemulangan WNI Overstayer (WNIO) oleh pemerintah Indonesia. Sepanjang tahun 2015 lalu, WNIO dari Malaysia menempati jumlah yang terbesar. Langkah pemulangan ini menindaklanjuti amanat Presiden Joko Widodo pada 17 Desember 2014. Dalam rangka pemulangan tersebut, Pemerintah Indonesia menyewa 5 pesawat maskapai Air Asia untuk memulangkan 1482 orang WNI Overstayer dari Malaysia tersebut. Mereka dipulangkan ke tanah air dan dikembalikan ke daerah asalnya seperti Jawa Barat, Jawa Timur dan Nusa Tenggara Barat. Meski demikian, masih banyak para WNI Overstayer yang masih menolak untuk dipulangkan ke tanah air (Tabloid PEDULI 2015).

Repatriasi WNI overstayer dan TKI undocumented yang menjadi fokus pemerintah Indonesia dilakukan karena kedua kasus ini yang yang paling banyak ditemukan. WNI Overstayer terbesar berada di kawasan Timur Tengah yakni di Arab Saudi, dimana jumlah repatriasi mencapai 2580 orang dan deportasi sebanyak 10484 orang. Selanjutnya WNIO dari Malaysia sebanyak repatriasi 3116 orang, dan deportasi sebanyak 76331 orang, berada di peringkat kedua. Mekanisme pemulangan WNI overstayer tersebut dilakukan melalui kerjasama dan dukungan pemerintah Malaysia. 
Saat para WNI overstayer ini tiba di Indonesia, mereka diserahkan kepada Kementerian Sosial untuk selanjutnya dipulangkan ke daerah asal mereka masing-masing. Selanjutnya, Kementerian Sosial dibantu oleh BP3TKI serta pemerintah daerah tempat asal WNI overstayer tersebut menyusun agenda dan program pemberdayaan untuk mengintegrasikan mereka kembali dalam lingkungan masyarakat.

Tabel 5 - Repatriasi WNI Overstayer dan TKI Undocumented (hingga Desember 2015)

\begin{tabular}{|c|c|c|c|c|}
\hline \multirow[b]{2}{*}{ Kawasan } & \multirow[b]{2}{*}{ Negara } & \multicolumn{3}{|c|}{ JUMLAH } \\
\hline & & $\begin{array}{c}\text { Repat- } \\
\text { riasi }\end{array}$ & Deportasi & Jumlah \\
\hline Timur Tengah & $\begin{array}{c}\text { Arab Saudi } \\
\text { Bahrain } \\
\text { Oman } \\
\text { Yordania } \\
\text { Kuwait } \\
\text { Qatar } \\
\text { PEA } \\
\text { Suriah } \\
\text { Mesir } \\
\text { Irak } \\
\text { Lebanon } \\
\end{array}$ & $\begin{array}{c}2580 \\
309 \\
971 \\
108 \\
101 \\
22 \\
1321 \\
441 \\
20 \\
1 \\
0 \\
\end{array}$ & $\begin{array}{c}10484 \\
0 \\
0 \\
0 \\
326 \\
0 \\
0 \\
0 \\
13 \\
0 \\
1 \\
\end{array}$ & $\begin{array}{c}13064 \\
309 \\
971 \\
108 \\
427 \\
22 \\
1321 \\
441 \\
33 \\
1 \\
1 \\
\end{array}$ \\
\hline Asia Timur & $\begin{array}{c}\text { Hongkong } \\
\text { Jepang } \\
\text { Taiwan } \\
\text { Korea Selatan } \\
\text { RRT } \\
\end{array}$ & $\begin{array}{c}96 \\
5 \\
93 \\
0 \\
30\end{array}$ & $\begin{array}{c}0 \\
0 \\
103 \\
0 \\
35 \\
\end{array}$ & $\begin{array}{c}96 \\
5 \\
196 \\
0 \\
65 \\
\end{array}$ \\
\hline $\begin{array}{c}\text { Amerika dan } \\
\text { Eropa }\end{array}$ & $\begin{array}{c}\text { Yunani } \\
\text { Turki } \\
\text { Rusia } \\
\text { Ceko } \\
\text { Belanda } \\
\text { Amerika Seri- } \\
\text { kat } \\
\end{array}$ & $\begin{array}{l}\mathbf{1 8} \\
\mathbf{0} \\
\mathbf{3} \\
\mathbf{1} \\
\mathbf{0} \\
\mathbf{0}\end{array}$ & $\begin{array}{c}1 \\
193 \\
1 \\
0 \\
82 \\
0\end{array}$ & $\begin{array}{c}19 \\
193 \\
4 \\
1 \\
82 \\
0\end{array}$ \\
\hline Asia Tenggara & $\begin{array}{c}\text { Malaysia } \\
\text { Brunei } \\
\text { Timor Leste } \\
\end{array}$ & $\begin{array}{c}3116 \\
2 \\
\mathbf{0} \\
\end{array}$ & $\begin{array}{c}76331 \\
2 \\
18 \\
\end{array}$ & $\begin{array}{c}79447 \\
4 \\
18 \\
\end{array}$ \\
\hline Afrika & Mesir & 20 & 13 & 33 \\
\hline
\end{tabular}




\begin{tabular}{|c|c|c|c|c|}
\hline & Australia & 0 & 19 & 19 \\
& Fiji & 12 & 0 & 12 \\
& Papua Nugini & 7 & 90 & 97 \\
\hline TOTAL & \multicolumn{3}{|c|}{96.989} \\
\hline
\end{tabular}

Dari pemaparan tabel di atas, terlihat bahwa WNI Overstayer terbesar di kawasan Timur Tengah yakni di Arab Saudi, dimana jumlah repatriasi mencapai 2580 orang dan deportasi sebanyak 10484 orang. Selanjutnya WNIO dari Malaysia sebanyak repatriasi 3116 orang, dan deportasi sebanyak 76331 orang, berada di peringkat kedua. Mekanisme pemulangan WNI Overstayer tersebut dilakukan melalui kerjasama dan dukungan pemerintah Malaysia. Saat para WNI Overstayer ini tiba di Indonesia, mereka diserahkan ke Kementerian Sosial untuk selanjutnya dipulangkan ke daerah asal mereka masing-masing. Selanjutnya, Kementerian Sosial dibantu oleh BP3TKI serta pemerintah daerah tempat asal WNI overstayer tersebut menyusun agenda dan program pemberdayaan untuk mengintegrasikan mereka kembali dalam lingkungan masyarakat.

Namun, gambaran berbeda terlihat pada WNI di luar negeri yang berstatus pelajar/mahasiswa. Data yang didapat merupakan hasil dari 29 kuesioner yang disebarkan ke para WNI yang bermukim di Jerman, Tokyo, San Fransisco, Paris, Jepang, Australia, Singapore, UK, USA, Korea Selatan. Mereka umumnya hanya mengalami persoalan terkait perpanjangan visa/ paspor. Menurut hasil survey tersebut kendala pelayanan dan informasi yang terbatas dari staff perwakilan, menjadi masalah bagi WNI tersebut. Bisa dikatakan, belum ada kasus spesifik yang menjangkau area perlindungan bagi WNI dalam kasus ini.

\section{Simpulan}

Bahwa model diplomasi perlindungan Pemerintah Indonesia terhadap WNI di luar negeri lebih diprioritaskan pada upaya perlindungan secara hukum, dengan kata lain ketika WNI mengalami suatu permasalahan atau kasus, pihak pemerintah Indonesia melakukan pendampingan dan perlindungan secara hukum sebagaimana panduan hukum yang dijadikan acuan dalam prosesnya selama ini dan pemerintah Indonesia bukan sebagai pihak yang menerima hukuman atas setiap kasus atau pelanggaran yang dilakukan oleh WNI. Saat ini pemetaan diplomasi 
perlindungan pemerintah Indonesia lebih banyak untuk kasus-kasus seperti Overstayer dan kasus TKI Undocumented. Dikarenakan tulisan ini merupakan intisari dari penelitian tahap awal, maka dari tulisan ini dapat dilakukan pengembangan materi di waktu mendatang dengan memfokuskan pada pemetaan model diplomasi perlindungan dengan lebih spesifik ke kantor perwakilan yang ada di wilayah-wilayah yang memiliki basis tenaga kerja ataupun WNI yang cukup besar seperti membuat studi perbandingan implementasi model perlindungan WNI di negara-negara Asia seperti Singapura, Hongkong, Malaysia, Taiwan atau dapat dilakukan di beberapa negara-negara di Eropa.

\section{Referensi}

\section{Jurnal dan Jurnal Daring}

Alexandra, Lina. 2012 "Indonesia and the Responsibility to Protect". The Pacific Review, 25 (1).

Borchard, Edwin M. 1913. "Basic Elements of Diplomatic Protection of Citizens Abroad". American Journal of International Law, 7 (3).

Dayang, Juan Enriquez, Jr., 2011. "International Migration Cooperation and Diplomacy: an Important Aspect of Global Governance". Peace Forum, 27 (2).

Forcese, Craig. 2006. "The Capacity to Protect: Diplomatic Protection of Dual Nationals in the War on Terror". European Journal of International Law, 17 (2): 374-384.

Keller, Gretta Nabbs. 2013. "Reforming Indonesia's Foreign Ministry: Ideas, Organisation and Leadership". Contemporary Southeast Asia, 35 (1): 56-82

Koban, Antonius Wiwan. 2010. "Meratapi Nasib Tenaga Kerja Indonesia di Luar Negeri. Update Indonesia: Tinjauan Bulanan Ekonomi, Hukum, Keamanan, Politik, dan Sosial". The Indonesian Institute: Center for Public Policy Research, December, V (8).

\section{Artikel Daring}

Kementerian Luar Negeri Republik Indonesia. 2011. "TKI antara Aset dan Pencitraan Negara" [online]. Tabloid Diplomasi Media Komunikasi dan Interaksi, 20 September 2011. http://www.tabloiddiplomasi. org/index.php/2011/09/20/tki-antara-aset-dan-pencitraan-negara/ [diakses 12 December 2017].

Kementerian Luar Negeri Republik Indonesia. t.t. "Undang-Undang Republik Indonesia, Nomor 21 Tahun 2007 Tentang Pemberantasan 
Tindak Pidana Perdagangan Orang” [online] http://pustakahpi. kemlu.go.id/dir_dok/UU-No.37.1999\%2O-tentang-Hubungan-LuarNegeri.pdf. [diakses 10 Agustus 2017].

Kementerian Luar Negeri Republik Indonesia. t.t. "Undang-Undang Republik Indonesia, Nomor 37 Tahun 1999 Tentang Hubungan Luar Negeri” [online]. http://pih.kemlu.go.id/files/UU_no_21 th 2007\%20tindak\%2opidana\%20perdagangan\%20orang.pdf [diakses 10 Agustus 2017].

Künzli, Annemarieke. t.t. "Exercising Diplomatic Protection: The Fine Line Between Litigation, Demarches and Consular Assistance" [online] http://www.zaoerv.de/66_2006/66_2006_2_a_321_350.pdf

United Nations. 2005. "Vienna Convention on Diplomatic Relations 1961 [online]. http://legal.un.org/ilc/texts/instruments/english/ conventions/9_1_1961.pdf [diakses 10 Agustus 2017].

United Nations. 2005. Vienna "Convention on Consular Relations 1963" [online]. http://legal.un.org/ilc/texts/instruments/english/ conventions/9_2_1963.pdf [diakses 10 Agustus 2017].

United Nations. 2006. "Draft articles on Diplomatic Protections" [online]. http://legal.un.org/ilc/texts/instruments/english/draft_ articles/9_8_2006.pdf [diakses 10 Agustus 2017].

United Nations Office on Drugs and Crime. t.t. "United Nations Convention Against Transnational Organized Crime and The Protocols Thereto" [online]. https://www.unodc.org/documents/ middleeastandnorthafrica/organised-crime/UNITED_NATIONS CONVENTION_AGAINST TRANSNATIONAL_ORGANIZED CRIME_AND_THE_PROTOCOLS_THERETO.pdf ${ }^{-}$[diakses $1 \overline{0}$ Agustus 2017].

\section{Lain-Lain}

Jaelani, Krisna. 2016. "Wawancara Kasubdit Pengawasan Kekonsuleran Kementrian Luar Negeri Republik Indonesia”, 17 Juni 2016.

Khair, Baiq Ro'idatul. 2015. "Perlindungan Hukum terhadap Tenaga Kerja Indonesia (TKI) yang Melebihi Batas Masa Tinggal (Overstay)". Fakultas Hukum Universitas Mataram.

Tabloid Peduli, 2015. "Diplomasi Perlindungan Luar Negeri: Mengapa WNI Overstayer Pulang?” Tahun II/Edisi 7/ Des 2015.

Tyas Retno Wulan. 2015. "Melindungi Buruh Migran Indonesia: Penguatan Strategi dari Daerah Asal". Seminar Nasional FISIP. Universitas Jenderal Soedirman. 